VOL.7, NO. 1, APRIL 2018

p-ISSN : 2337-537X;

\title{
PERLAKUAN AKUNTANSI DANA PIHAK KETIGA PT. BPR SURYAJAYA UBUD
}

\author{
Ida Ayu Savitri \\ Jurusan Akuntansi Program Diploma III, \\ Universitas Pendidikan Ganesha, Singaraja \\ Email : dayusavitri62@gmail.com
}

\begin{abstract}
Abstrak
Penelitian ini bertujuan untuk mengetahui Perlakuan Akuntansi Dana Pihak Ketiga pada PT. BPR Suryajaya Ubud. Subyek penelitian ini adalah PT. BPR Suryajaya Ubud, sedangkan obyek penelitian ini adalah Perlakuan Akuntansi Dana Pihak Ketiga. Metode pengumpulan data menggunakan metode wawancara, dokumentasi dan observasi. Penelitian ini menggunakan analisis data deskriptif kualitatif. Hasil penelitian menunjukan bahwa perlakuan akuntansi dana pihak ketiga pada PT. BPR Suryajaya Ubud telah dilakukan dengan baik, namun perlu di tingkatkan lagi agar menjadi lebih baik. Dengan menggunakan sistem pencatatan berbentuk Cash Basis, proses pengakuan atas tabungan dan deposito pada PT. BPR Suryajaya Ubud dapat dikatakan sederhana sehingga mudah diterapkan. Perlakuan akuntansi tersebut terdiri atas (1) Pengukuran (2) Pengakuan (Recognition) (3) Penyajian (Presentation). Meskipun sudah menggunakan sistem komputerisasi dalam setiap transaksi dan pelaporannya, namun sangat diperlukan perhatian dan ketellitian terhadap beberapa hal. Seperti penentuan tanggal jatuh tempo deposito atau perhitungan besarnya bunga pada tabungan dan deposito.
\end{abstract}

Kata kunci : Perlakuan Akuntansi, BPR

\begin{abstract}
The purpose of this research is to knowing about accounting treatment given to Third Party's Finance on the PT. BPR Suryajaya Ubud. The subject of this study was PT. BPR Suryajaya Ubud and the object is the accounting treatment given to Third Party's Finance. The methods of collecting data being used interview, documentation and observation. This research being used descriptive qualitative analysis. The result of this study shows that the accounting treatment of third party's finance at PT. BPR Suryajaya Ubud has well, but need improved to be better. By using the system of recording Cash Basis, the process of recognition of savings and deposits at PT. BPR Suryajaya Ubud can be said simple so easy to apply. The accounting treatment consists of (1) Measurement (2) Recognition (3) Presentation. Although already using the computerized system in every transaction and reporting, but it is necessary attention and detail to several things.
\end{abstract}

Keywords : Accounting treatment, BPR

\section{PENDAHULUAN}

Seiring perkembangan jaman maka seluruh aspek kehidupan mau tidak mau juga harus mengikuti perkembangannya, tidak terkecuali dengan perekonomian.

Dalam perkembangan ekonomi kini sudah banyak perusahaan-perusahaan yang berdiri, baik dalam bidang bisnis maupun pelayanan pada masyarakat yang masih meperhatikan profit. Demikian pula dengan lembaga keuangan, perekonomian yang baik menyebabkan lembaga keuangan berkembang dalam masyarakat.

BPR adalah salah satu lembaga keuangan yang yang berjasa dalam membantu perekonomian. Menurut UU No. 10 tahun 1998 BPR adalah lembaga keuangan yang memiliki usaha menghimpun dana dari masyarakat dalam bentuk simpanan berupa deposito, tabungan dan/atau bentuk lainnya yang dipersamakan dengan itu memberikan kredit. 
VOL.7, NO. 1, APRIL 2018

p-ISSN : 2337-537X;

Salah satu BPR yang kini sedang berkembang di Bali adalah BPR Suryajaya Ubud yang sering dikenal dengan Bank Surya Ubud. Melihat perkembangannya yang signifikan terntu karena pengelolaan perusahaan terhadap sumber dana dan SDM yang baik, namun perlu juga diperhatikan apakah pengelolaan dengan cara tersebut akan tetap memberikan pengaruh yang baik kedepannya bagi perusahaan.

Bank Perkreditan Rakyat (BPR) adalah bank yang melaksanakan kegiatan usaha secara konvensional atau berdasarkan prinsip syariah yang dalam kegiatannya tidak memberikan jasa dalam lalu lintas pembayaran. Artinya disini kegiatan BPR jauh lebih sempit jika dibandingkan degan kegiatan Bank Umum (Kasmir. 2012).

Bagi sebuah bank sebagai suatu lembaga keuangan, dana merupakan darah dan persoalan paling utama. Dana bank merupakan sejumlah uang yang dimiliki atau aktiva lancar yang dikuasai suatu bank dalam kegiatan operasionalnya dan setiap waktu dapat diuangkan. Tidak terkecuali dengan PT. BPR Suryajaya Ubud juga melakukan kegiatan menghimpun dana dari pihak ketiga. Menurut Lukman Dendawijaya (2009:46) dana pihak ketiga adalah dana berupa simpanan dari masyarakat yang merupakan sumber dana terbesar yang paling diandalkan oleh bank.

Khusus pada PT. BPR Suryajaya dana yang dihimpun berupa tabungan dan deposito kemudian disalurkan kemasyarakat berbentuk kredit.

Pada Bank Surya sendiri meberikan bunga yang bervariasi sesuai dengan jangka waktu dari deposito yaitu bunga $6,5 \%$ untuk jangka waktu 1 bulan, $7 \%$ jangka waktu 3 bulan, jangka waktu 6 bulan 7,5\%, jangka waktu 12 bulan sebesar 8\% dan 8,5\% untuk diatas 12 bulan. PT. BPR Suryajaya Ubud memiliki beberapa produk tabungan. Pada setiap produk tabungan diberikan bunga sebesar $4 \%$ untuk tabungan suryajaya dan $6 \%$ untuk jenis tabungan lainnya.

Mengingat dana merupakan darah dan sesuatu yang sangat berpengaruh terhadap perkembangan lembaga keuangan, maka diperlukan adanya pencatatan akuntansi maupun pengelolaan yang tepat untuk menjaga kelangsungan perusahaan. Dengan dasar tersebut sangat penting menilai perlakuan akuntansi terhadap dana pihak ketiga yang akan berpengaruh pada kelangsungan hidup suatu lembaga keuangan. Berdasarkan uraian latar belakang diatas maka penulis tertarik untuk meneliti Perlakuan Akuntansi Dana Pihak Ketiga Pada PT. BPR Suryajaya Ubud.

\section{METODE PENELITIAN}

Tujuan diadakannya penelitian ini adalah untuk memperoleh informasi sesuai dengan judul penelitian yakni Perlakuan Akuntansi Dana Pihak Ketiga Pada PT. BPR Suryajaya Ubud. Adapun sistematika yang dilakukan adalah menentukan lokasi penelitian yakni pada PT. BPR Suryajaya Ubud, kemudian merumuskan masalah yang akan diteliti agar permasalahan tersebut dapat dijawab maka diperlukan kajian teori yang akan melandasi penelitian ini. Setelah itu dilakukan pengumpulan data. Pada penelitian ini, teknik analisis data yang digunakan adalah analisis data deskriptif kualitatif dan deskriptif kuantitatif. Deskriptif kualitatif yaitu penelitian memberikan penjelasan atau menguraikan, menggambarkan, dan mendeskripsikan mengenai Perlakuan Akuntansi Dana Pihak Ketiga pada PT. BPR Suryajaya Ubud, sedangkan deskriptif kuantitatif yaitu teknik penelitian dengan cara menghitung bunga deposito dan denda deposito yang diperoleh oleh PT. BPR Suryajaya Ubud.

Subyek yang diteliti adalah PT. BPR Suryajaya Ubud, sedangkan obyek penelitian adalah hal yang akan diteliti yaitu Perlakuan Akuntansi Dana Pihak Ketiga. Jenis data yang digunakan adalah data kualitatif dan kuantitatif. Data kualitatif adalah data yang tidak berupa angka tetapi memberikan informasi tentang pencatatan laporan keuangan seperti jurnal, buku besar, sampai laporan laba/rugi dan neraca. Sedangkan data kuantitatif merupakan data yang berupa angka-angka mengenai pencatatan akuntansi dana pihak ketiga pada PT. BPR Suryajaya Ubud.

Sumber data yang digunakan dalam penelitian ini adalah data primer dan sekunder. Data primer merupakan data yang langsung diperoleh dari perusahaan melalui pimpinan 
atau karyawan yang berhak memberikan data mengenai perlakuan akuntansi dana pihak ketiga pada PT. BPR Suryajaya Ubud, sedangkan data sekunder yaitu data yang diperoleh dari dokumen-dokumen yang telah ada seperti bilyet deposito dan struktur organisasi PT. BPR Suryajaya Ubud.

Untuk metode pengumpulan data menggunakan metode wawancara, dokumentasi dan observasi. Metode wawancara merupakan cara pengumpulan dara dengan cara Tanya jawab secara langsung dengan pimpinan atau karyawan ataupun pihak-pihak yang ada hubungannya dengan data yang diperlukan. Metode dokumentasi merupakan cara pengumpulan data dengan peninggalan tertulis seperti arsip, buku tentang teori, pendapatan, dalil dan hukum serta lain-lain yang berhubungan dengan perlakuan akuntansi dana pihak ketiga pada PT. BPR Suryajaya Ubud. Sedangkan observasi merupakan pengumpulan data yang langsung dilakukan dengan pengamatan dan pencatatan langsung terhadap obyek yang diteliti berupa perlakuan akuntansi dana pihak ketiga pada PT. BPR Suryajaya Ubud.

\section{HASIL PENELITIAN DAN PEMBAHASAN}

\section{Perlakuan Akuntansi Tabungan pada PT. BPR Suryajaya Ubud :}

a. Pengukuran

Didalam hal pengukuran terhadap tabungan, pencatatan yang dilakukan PT. BPR Suryajaya Ubud pada saat penyetoran dan penarikan tabungan adalah sebagai berikut :

1) Pada saat penyetoran Tabungan Suryajaya dari nasabah.

Pada saat bank menerima tabungan berupa setoran dana dari nasabah, teller akan mencatat penerimaan tersebut dalam slip setoran sebesar nilai nominal. Slip setoran dibuat rangkap 2 (dua). Pihak bank akan mengarsipkan 1 (satu) slip setoran dan slip setoran yang ke 2 (dua) akan diberikan kepada nasabah untuk disimpan. Dengan adanya penerimaan dana ini, maka menyebabkan bertambahnya saldo kas pada PT. BPR Suryajaya Ubud. Berikut pencatatannya : Kas

$$
\text { Rp. } x x x
$$

$$
\text { Tabungan Suryajaya Rp. Xxx }
$$

Pencatatan yang dilakukan dengan mendebet perkiraan kas karena adanya penerimaan dana berupa setoran tabungan dari nasabah yang menyebabkan bertambahnya kas pada PT. BPR Suryajaya Ubud dan mengkredit perkiraan tabungan nasabah. Bagi suatu bank tabungan merupakan hutang atau kewajiban sehingga dicatat disebelah kredit.

2) Pada saat penarikan Tabungan Suryajaya oleh nasabah.

Pada saat nasabah menarik dana, teller akan mencatat penarikan tersebut dalam slip penarikan sebesar nilai nominal. Slip penarikan dibuat rangkap 2 (dua). Pihak bank akan mengarsipkan 1 (satu) slip penarikan dan slip penarikan yang ke 2 (dua) akan diberikan kepada nasabah untuk disimpan. Dengan adanya penarikan atau pengambilan dana ini, maka menyebabkan berkurangnya saldo kas pada PT. BPR Suryajaya Ubud. Berikut pencatatannya :

Tabungan Suryajaya Rp. xxx

$$
\text { Kas Rp. Xxx }
$$

Pengambilan atau penarikan tabungan akan mengurangi kewajiban atau hutang bank atas tabungan nasabah, karena kewajiban berkurang maka tabungan dicatat disebelah debet dan kas akan berkurang maka dari itu dicatat dibagian kredit. Dalam hal pengukuran untuk setiap jenis tabungan pencatatannya sama namun hanya berbeda pada perhitungan bunga dan perhitungan pembayaran bunganya saja. 
b. Pengakuan

Perlakuan Akuntansi yang diterapkan oleh PT. BPR Suryajaya Ubud adalah menggunakan sistem Cash Basis yaitu pencatatan transaksi keuangan dilakukan pada saat transaksi yang bersangkutan telah diselesaikan secara tunai. Maka dalam akuntansi akan dilakukan pencatatan saat terjadi penerimaan dan pengeluaran kas secara tunai.

c. Penyajian

d. Tabungan merupakan bentuk dana dari masyarakat yang dititipkan sementara pada bank bersangkutan. Sehingga tabungan dikategorikan sebagai kewajiban atau hutang.

Tabungan disajikan dineraca disisi kredit, karena tabungan merupakan kewajiban pihak bank kepada masyarakat. Setiap setoran akan dicatat sebesar nilai nominal setoran sebagai penerimaan kas yang selanjutnya akan disajikan sebagai kewajiban sebesar nilai nominal tersebut. Nilai kewajiban dalah saldo yang ditambah bunga yang diperhitungkan. Untuk setiap nominal bunga dikreditkan pada rekening tabungan nasabah.

\section{berikut :}

\section{Perlakuan Akuntansi Deposito Pada PT. BPR Suryajaya Ubud adalah sebagai}

a. Pengukuran

Perlakuan akuntansi deposito pada PT. BPR Suryajaya Ubud memiliki produk simpanan berjangka atau deposito yaitu 1 bulan, 3 bulan, 6 bulan, 12 bulan dan lebih dari 12 bulan. Simpanan berjangka atau deposito akan dikenakan penalty saat nasabah melakukan pencairan sebelum jatuh tempo. Besar penalty yang dikenakan adalah sebesar $1 \%$ dari pokok deposito. Besar bunga deposito ditentukan berdasarkan jangka waktu dan tidak dipengaruhi oleh nominal yang disetorkan, dapat dilihat pada tabel berikut :

\begin{tabular}{|l|l|l|}
\hline o & angka Waktu & \multicolumn{1}{|c|}{ uku Bunga } \\
\hline & bulan &, $5 \%$ \\
\hline & bulan & $\%$ \\
\hline & bulan &, $5 \%$ \\
\hline & 2 bulan & $\%$ \\
\hline & 12 bulan &, $5 \%$ \\
\hline
\end{tabular}

Pada saat perhitungan bunga deposito berjangka, dalam menghitung bunga minimal mengendap selama 1 bulan. Misalnya deposito dibuka tanggal 31 Maret, maka tanggal jatuh tempo bunga adalah tanggal 30 April, 31 Mei, 30 Juni dan seterusnya.

Tetapi jika deposito dibuka tidak pada tanggal akhir bulan, maka jatuh tempo bunga sama dengan tanggal pembukaan deposito, contoh deposito dibuka tanggal 14 Maret untuk deposito 3 bulan, maka jatuh tempo bunganya pada tanggal 14 April, 14 Mei dan 14 Juni.

Pengakuan

Perlakuan Akuntansi deposito yang diterapkan pada PT. BPR Suryajaya Ubud adalah sistem Cash Basis yaitu pencatatan transaksi keuangan yang bersangkutan telah diselesaikan secara tunai. Maka dalam akuntansi akan dilakukan pencatatan apabila sudah terjadi penerimaan dan pengeluaran kas.

$$
\begin{aligned}
& \text { 1. Pada saat penyetoran deposito dari nasabah } \\
& \text { Kas }
\end{aligned}
$$

Deposito nasabah $\quad$ Rp. $x x x$

Pencatatan dilakukan dengan mendebet perkiraan kas karena adanya penerimaan kas atas setoran deposito dari nasabah yang menyebabkan bertambahnya saldo kas PT. BPR 
Suryajaya Ubud, dengan mengkredit perkiraan deposito nasabah yang merupakan suatu kewajiban atau hutang PT. BPR Suryajaya Ubud kepada nasabah.

2. Pada saat pencairan atau penarikan deposito oleh nasabah.

Teller akan membuat slip penarikan atas deposito, slip penarikan ini merupakan bukti pengeluaran kas PT. BPR Suryajaya Ubud yang berisi besarnya jumlah uang yang akan dikeluarkan dari jenis transaksi ini. Berikut adalah pencatatannya :

$\begin{array}{ll}\text { Deposito nasabah } & R p . x x x \\ \text { Biaya Bunga } & R p . x x x \\ \text { Kas } & R p . x x x\end{array}$

Pencatatan pada saat pengambilan atau penarikan deposito yang telah jatuh tempo akan mengurangi kewajiban bank atas deposito yang dibuat oleh nasabah. Karena kewajiban berkurang maka perkiraan deposito dan biaya bunga dicatat disebelah debet, sedangkan kas juga akan berkurang dan dicatat di sebelah kredit. Perlakuan untuk penarikan deposito ini juga dilakukan menggunakan sistem Cash Basis.

Adapun transaksi yang sering terjadi untuk simpanan deposito. Yaitu pencairan atau penarikan deposito sebelum jatuh tempo yang dapat mengganggu lukuiditas bank, sebab bank sudah menyiapkan dana untuk membayarkan sesuai dengan jadwal pembayaran. Oleh karena itu bank akan menerapkan penalty tertentu terhadap deposan (pemilik deposito) bila penarikan dilakukan sebelum tanggal jatuh tempo. Penalty yang dibayar nasabah adalah sebesar 1\% dari pokok deposito di PT. BPR Suryajaya Ubud. Deposito dicatat sebagai pendapatan lain-lain bank.

\section{Simpulan dan saran}

Hasil akhir dari siklus akuntansi adalah laporan keuangan. Laporan keuangan menggambarkan tentang keadaan keuangan perusahaan sehingga perlu disajikan dengan relevan, laporan keuangan harus dibuat secara teliti dan diajikan secara menyeluruh. Dalam hubungannya dengan laporan keuangan, tabungan dan deposito terletak di laporan neraca pada bagian pasiva karena tabungan dan deposito merupakan kewajiban atau hutang bagi PT. BPR Suryajaya Ubud yang harus dibayar kepada nasabah.

Antara aktiva dan pasiva harus dapat menunjukan laporan keuangan yang balance atau seimbang agar laporan keuangan dapat dijadikan dokumen pembukuan yang dipercaya kebenarannya. 
VOL.7, NO. 1, APRIL 2018

p-ISSN : 2337-537X;

\section{DAFTAR PUSTAKA}

Erni Sulindawati,dkk. 2013. "Intermediete Accounting I berserta soal latihan". Singaraja : Percetakan Undiksha.

Irfan Fahmi. 2011. "Analisis Laporan Keuangan”. Bandung : Alfabeta anggota IKAPI.

Kasmir.2003. "Bank dan Lembaga Keuangan Lainnya”. Jakarta : PT. Raja Grafindo.

Lapoliwa,N.,dkk. 2005. "Akuntansi Perbankan Transaksi Bank Dalam Valuta Rupiah". Jakarta : Institut Bankir Indonesia.

Muliyadi. 1993. "Sistem Akuntansi". Jakarta : STIE.

Sofyan Syafri. 2012. "Teori Akuntansi Edisi Revisi 2011”. Jakarta : Rajawali Pers.

Sudarma, Agus. 2015. Perlakuan Akuntansi Dana Pihak Ketiga Khususnya Deposito Pada LPD Desa Pekraman Penglatan Tugas Akhir (tidak dipublikasikan).

Toto Sucipto,dkk, 2008. "Siklus Akuntansi Perusahaan". Jakarta : Yudisthira.

Tripalupi, Lulup Endah. 2013, "Buku Ajar Akuntansi Perbankan Seri Sumber Dana Bank". Singaraja : Undiksha Press.

Undang - undang No 10 Tahun 1998 tentang Bank Perkreditan Rakyat tersedia pada http://id.wikisource.org/wiki/Undang-undang-Republik-Indonesia-tahun1998// diakses tanggal 15 Maret 2017 